\title{
Use Chou's 5-Steps Rule to Reveal Why SARS + MERS = COVID-19?
}

\section{Cemil Koyunoğlu*}

Engineering Faculty, Energy Systems Engineering Department, Yalova University, Turkey

*Corresponding author: Cemil Koyunoğlu, Engineering Faculty, Energy Systems Engineering Department, Cinarcik Road 5th km, 77200-Center Campus, Yalova University, Turkey, Tel: +90-212-285-3939; E-mail: cemil.koyunoglu@yalova.edu.tr

Received: 30 Mar, 2020 | Accepted: 20 Apr, 2020 | Published: 25 Apr, 2020

Citation: Koyunoğlu C (2020) Use Chou's 5-Steps Rule to Reveal Why SARS + MERS = COVID-19?. J Biochem Analyt Stud 4(2): dx.doi.org/10.16966/25765833.121

Copyright: (C) 2020 Koyunoğlu C. This is an open-access article distributed under the terms of the Creative Commons Attribution License, which permits unrestricted use, distribution, and reproduction in any medium, provided the original author and source are credited.

\begin{abstract}
Why does science limit lying like other fields? Is it because of human life? or is it because of thinking that life is a gamble? Of course, there may be those who think of what these problems have to do with COVID-19. The answer is Hydroxychloroquine and Azithromycin, one of which is therapeutic drugs of SARS and the other is MERS. Mixing and usage is a $100 \%$ improvement in French patients. Einstein argues that the word "God does not play dice" cannot be attributed to the fact that mistakes made in science may be in the hands of people at risk of leading people to death. In otherwords, the mistake of the events cannot be attributed to God. As in ancient times, the perception that the appointment of unskilled personnel is based on earning money only in areas where human resources are insufficient, in otherwords, unfortunately, the global out breaks are perceived as wrong and whether God will kill people on probability. What I want to explain is that the fact that COVID-19 is known as a derivative of SARS and MERS is not based on the curiosity of whether it behaves with test kits, that is, whether its diagnosis is dice. Clear things should be emphasized and no action should ever be taken. We see why the logic of $1+1=2$ is not evaluated in scientific results and is not addressed in patients who take medications that improve SARS and MERS. If the mixture of hydroxychloroquine and azithromycin heals the disease, why it is not important for the administrators at the state level to be the first step in providing these drugs for free by taking human health to the forefront. In otherwords, the fact that appointments in the state are not based on those who know the subject leads to the emergence of unscientific steps in taking epidemic measures. It should not be thought that people should be blamed here. It should be considered at the forefront of structuring in which human health is considered instead of interest. I wish you healthy days.
\end{abstract}

\section{Introduction}

Let's first look briefly on the study recently published on February namely "Hydroxychloroquine and azithromycin as a treatment of COVID 19: results of an open-labelnon-randomized clinical trial" and articles' authors are Philippe Gautret, Jean-Christophe Lagier, Philippe Parola, Van ThuanHoang, Line Meddeb, Morgane Mailhe, Barbara Doudier, Johan Courjon, Valérie Giordanengo, Vera Esteves, Vieira Hervé, Tissot Dupont, Stéphane Honoré, Philippe Colson, Eric Chabrière, Bernard La, Scola Jean-MarcRolain, Philippe Brouqui, Didier Raoult.

To develop a useful predictor for a biological system, one needs to follow Chou's 5-steps rule [1] to go through the following five steps (see, e.g., (2): (1) selector construct a valid benchmark data set to train and test the predictor; (2) represent the samples with an effective formulation that can truly reflect their intrinsic correlation with the target to be predicted; (3) introduce or develop a powerful algorithm to conduct the prediction; (4) properly perform cross-validation tests to objectively evaluate the anticipated prediction accuracy; (5) establish a user-friendly web-server for the predictor that is accessible to the public. Papers presented for developing a new sequenceanalyzing method or statistical predictor by observing the guidelines of Chou's 5-step rules have the following notable merits: (1) crystal clear in logic development, (2) completely transparent in operation, (3) easily to repeat the reported results by other investigators, (4) with high potential in stimulating other sequence-analyzing methods, and (5) very convenientto be used by the majority of experimental scientists (3)."

Using graphic approaches to study biological and medical systems can provide an intuitive vision and useful insights for helping analyze complicated relations there in as shown by the eight master pieces of pioneering papers from the then Chairman of Nobel Prize Committee Sture Forsen (see, e.g., [3,4], and many follow-up papers (see, e.g., [5] and a long list paper cited in a comprehensive review [6])

\section{Study Results In Detail}

The study indicates that hydroxychloroquine and chloroquine are effective in SARS-CoV-2 experimentally. It has also been effective in COVID 19 patients in China. The study was evaluated according to the hydroxychloroquine effect of viral loads of the virus on the respiratory tract.

In the study, viral loadings of nasopharyngeals wabs were determined by using $600 \mathrm{mg}$ hydroxychloroquine daily between 1-16 March in COVID 19 patients living in France. Azithromycin addition was made depending on their clinical appearance. Patients who 
were not treated or refused treatment were considered negative. The presence or absence of the virus has been determined from day 6 [7].

Inaddition to the asymptomatic symptoms, 6 patients evaluated had 22 patients with upper tract infection and eight had lower respiratory tract infections [7].

20 of 38 patients were treated. What is important here is that after D6 inclusion, viral carriers are reduced and the virus transport time in the body is lower than previous studies. Also, azithromycin added to hydroxychloroquine is effective in virus elimination [7] (Figure 1 and 2).

Twenty cases were treated in this study and showed a significant reduction in a viral carrier in post-D6 inclusion compared to controls, and significantly lower mean transport time than reported by untreated patients in the literature. Azithromycin added to hydroxychloroquine is significantly more effective for virus elimination [7].

As a result of the study, the researchers showed that the use of hydroxychloroquine has a significant relationship with significant viral load reduction or loss in patients with COVID 19 and this effect is further increased with azithromycin [7].

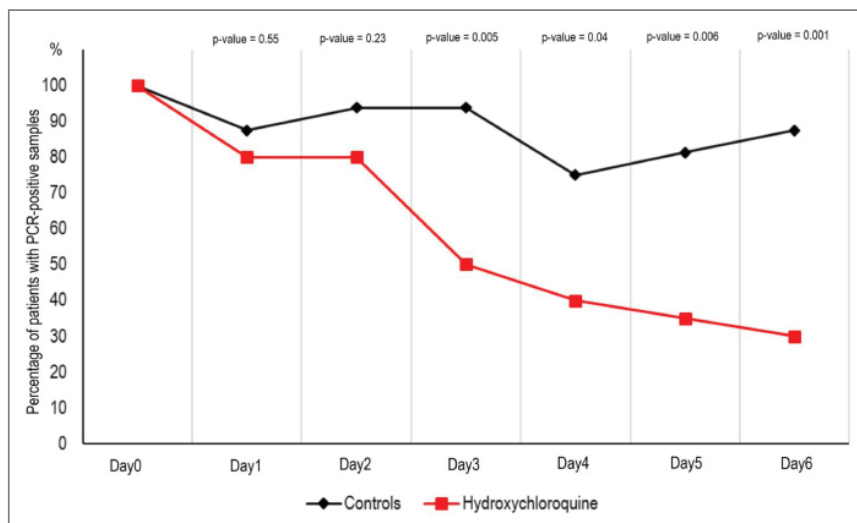

Figure 1: "Percentage of patients 6 todays after the inclusion of PCR positive nasopharyngeal samples in COVID-19 control patients and COVID-19 patients treated with hydroxychloroquine" [7].

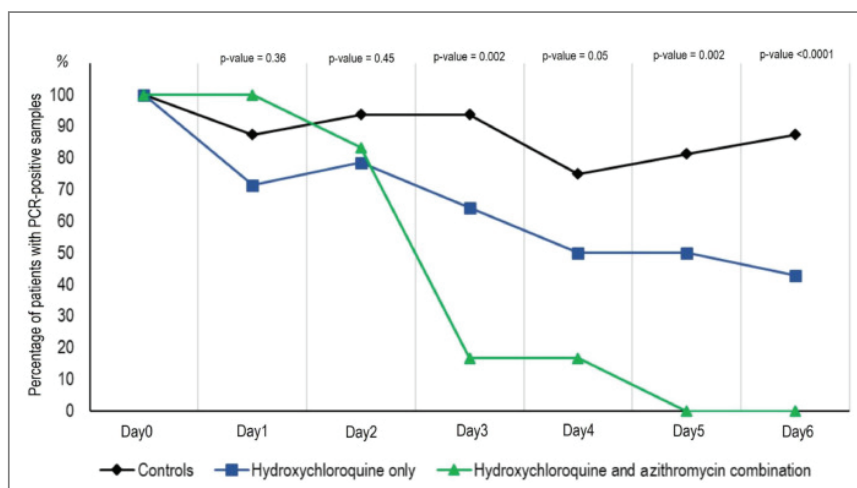

Figure 2: "Percentage of patients with PCR-positive nasopharyngeal samples from inclusion to day 6 post-inclusion in COVID-19 patients treated with hydroxychloroquine only, in COVID 19 patients treated with hydroxychloroquine and azithromycin combination, and in COVID 19 control patients" [7].
As shown in a series of recent publications (see, e.g., $[8,9]$ ) in demonstrating new findings or approaches, user-friendly and publicly accessible web-servers will significantly enhance their impacts $[2,10]$, driving medicinal chemistry into an unprecedented revolution [11], we shall make efforts in our future work to provide a web-server to display the findings that can be manipulated by users according to their need.

\section{Conclusion}

If the infected hosts of the SARS and MERS virus are pigs and camels, the fact that their mutated states are more lethal than COVID-19 shows us that we should be in a more fortunate process. Solution; Let us emphasize once again that it is necessary to seek scientific methods rather than criticizing. Realizing the possibility that two different individuals can meet at a common point here, Chou's 5-step rule will prove to be superior by using his mind against a creature that humanity cannot see. This should not make us forget that the superiority of the human species to COVID-19 is just the mind.

\section{References}

1. Chou KC (2011) Some remarks on protein attribute prediction and pseudo amino acid composition. J Theor Biol 273: 236-247.

2. Chou KC (2019) Advance in predicting subcellular localization of multi-label proteins and its implication for developing multi-target drugs. Curr Med Chem.

3. Chou KC, Forsén S (1980) Diffusion-controlled effects in reversible enzymatic fast reaction systems-- critical spherical shell and proximity rate constant. Biophys Chem 12: 255-263.

4. Chou KC, Forsen S (1980) Graphical rules for enzyme-catalysed rate laws. Biochem J 187: 829-835.

5. GP Zhou, MH Deng (1984) An extension of Chou's graphic rules for deriving enzyme kinetic equations to systems involving parallel reaction pathways. Biochem J 222: 169-176.

6. Chou KC (1988) Low-frequency collective motion in biomacromolecules and its biological functions. Biophys Chem 30 : 3-48.

7. Gautret P, Lagier JC, Parola P, Hoang VT, Meddeb L, et al. (2020) Hydroxychloroquine and azithromycin as a treatment of COVID-19: results of an open-label non-randomized clinical trial. Int J Antimicrob Agents: 105949.

8. Chen W, Tang H, Ye J, Lin H, Chou KC (2016) iRNA-PseU: Identifying RNA pseudouridine sites. Mol Ther Nucleic Acids 5: e332.

9. Liu B, Fang L, Long R, Lan X, Chou KC (2016) iEnhancer-2L: a twolayer predictor for identifying enhancers and their strength by pseudo k-tuple nucleotide composition. Bioinformatics 32: 362-369.

10. Chou KC (2015) Impacts of bioinformatics to medicinal chemistry Med Chem 11: 218-234.

11. Chou KC (2017) An Unprecedented Revolution in Medicinal Chemistry Driven by the Progress of Biological Science. Curr Top Med Chem 17: 2337-2358. 